\title{
Two-Phase Development of the Instructional Teacher Leadership Rating Scale for Building School Capacity (ITLRSBSC): Model Emergence through Pervasive Empirical Grounding and Mixed Method Evaluation Design
}

\author{
Jeffrey Lear ${ }^{1}$, Steven Godin ${ }^{2}$, Sean Werner ${ }^{1}$, Mark Flamisch ${ }^{3}$ \\ East Stroudsburg University of $P A^{1}$ \\ Department of Health Studies, East Stroudsburg University of $P A^{2}$ \\ Whitehall-Coplay School District ${ }^{3}$ \\ United States
}

\begin{abstract}
Factors contributing to school improvement continue to garnish international interest. The problem is school leadership teams possess little information on 'distributed leadership systems' which engage teachers in sustainable school reform. This manuscript continues a line of literature initiated to develop an instrument for measuring instructional teacher leadership behaviors conducive to building school capacity for improvement (ITLRSBSC) [1]. Instructional Leadership studies using successful rating scales (e.g. PIMRS, VAL-ED) have shed light on 'what' principal behaviors lead to school improvement. Little is known about 'how' and 'why' instructional teacher leadership behaviors are engaged. A perceived augmentation of principle instructional leadership is theoretically superimposed on the design of the ITLRSBSC instrument. In phase one, a $Q$-set will systematically emerge from a) empirical literature and b) mixed method evaluation processes on interview and PIMRS data. This paper details the development of interview questions from the convergence of instructional leadership conceptual models. In phase two of the study, ITLRSBSC behaviorally anchored dimensions and subscales will be constructed utilizing the transferred $Q$-set within BARS methodology. The phase one pre-instrument correlation of distributed instructional leadership behaviors is purposed to increase post development ITLRSBSC instrument validation scoring. All educators and researchers engaging teacher leaders in building school instructional leadership capacity will benefit from this publication.
\end{abstract}

\section{Introduction}

Instructional leadership studies seek to increase knowledge on specific school leadership practices with the greatest effect on learning outcomes. A connection between school leadership and organization performance may be captured by analyzing the bidirectional behavioral functions of educators practicing in instructional leadership. While instructional leadership investigations have contributed greatly to understanding how principal behaviors affect student outcomes, teachers have the greatest impact on student achievement. It is clear instructional leadership responsibilities cannot be placed on a single individual [2].

Recent instructional leadership studies draw conclusions toward three specific outcomes; student academic achievement, social development, and student empowerment [3]. Relative to the classroom setting, principal instructional leadership is second only to teacher effects on student outcomes [2][4]. Principal instructional leadership mediating variables can be used to illustrate how principal leadership behaviors influence teacher behaviors, which in turn, affect student learning [4][5]. For these reasons, leadership models, conceptual frameworks, and instrumentation need to be refined to reflect effective teacher leadership activities within a distributed leadership setting. By refining frameworks to include constructs of teacher instructional leadership, the greatest contributing factor on student outcomes can be further specified.

\section{Statement of the problem}

School Leadership has been widely studied through the paradigm of individual-level outcomes. As schools seek the favorable aspects of organic organizational models, analysis of cooperating participants needs to be studied under their professional networking structures. Instructional leadership in the school setting has recently been 
viewed as an administrative responsibility which the principal is invested. This research perspective has created blank spots in the understanding of how leadership functions foster improvements in learning. [6]. It is imperative to investigate sustainable school improvement utilizing a perspective encapsulating both principal instructional leadership and teacher leadership. Although teacher leadership has been conceptualized for some time, some studies show leadership "titles" among teachers have yielded little or no benefit to sustainable school reform [7]. Current research on principal instructional leadership and teacher leadership centers on bringing about sustainable school reform. Through this investigation, a team-based correlational analysis will occur on perceptions of leadership sustaining activity.

The problem is teachers and administrators in our schools have little information on working distributed leadership systems engaging teachers in instructional teacher leadership activities toward sustainable school reformation. We know principal, teacher, and coach instructional leadership all contribute in a distributed leadership system for the improvement of student learning [8]. Although we know much about what leadership practices bring about instructional change, we have an incomplete picture on how and why leaders engage in their leadership behaviors [6][8]. As a preliminary step to causation, significance in correlation of bidirectional behavioral functions must be identified in complex educational organizational environments. By identifying these relationship constructs, educators may build an inventory of contextual specific instructional leadership practices. The in-progress two-phase processes that follow details the authors approach to the inquir

\section{Purpose of this in-progress study}

The purpose of this two-phase mixed methods study is to develop an instrument that measures the perceptions of instructional teacher leadership behaviors in schools. This research will begin to fill blank spots of knowledge in leadership by reporting on leadership team perceptions of teacher leadership activities consistent with a distributed responsibility of instructional leadership. This information is important to improve understanding of how teacher leadership activity sustains school improvement. Sustained school improvement is depicted by Lambert [9] as a result of sustaining leadership capacity. Sustainable school improvement activities based upon teacher leadership roles are interesting to educators and policymakers [9]. This study will further the understanding of specific instructional teacher leadership school practices which have demonstrated sustainable leadership capacities characterized by the functions of shared vision, team learning, and systems thinking [10].

\section{The need for instrumentation on specific teacher leadership behavior}

An instrument does not exist to measure the selfreport perception of teachers regarding the activity of instructional teacher leadership for the purpose of building capacity in schools. The end result of this two-phase study is to develop an instrument to measure teachers' leadership behavior in building instructional leadership capacity. Quality instrumentation exists to measure principal instructional management behaviors in the form of a perception questionnaire [5]. With a current emphasis on teacher leadership and the development of conceptual frameworks for distributed leadership responsibilities, it is appropriate to develop this instrument [4][5]. The Teacher Leadership Inventory (TLI) instrument was developed to measure teacher leadership in a broad spectrum. Although a pioneering instrument, it was not designed specifically to measure instructional leadership behaviors of teachers fulfilling leadership roles for capacity building activity toward school improvement [11].

\section{Research questions}

In order to provide a closer look at instructional teacher leadership perceptions, the following questions specifically address teacher leadership behavior within a school leadership capacity model.

1. What are teachers' perceptions regarding distributed responsibility for fostering collective responsibility in the learning of all students and adults in the school?

2. What measureable behaviors do teachers exhibit which are characteristic of teachers' roles in instructional management?

3. What measureable variations exist in instructional teacher leadership for the pursuit of building school capacity for learning?

The goal is to identify dimensions, sub-constructs, and operational behaviors accurately depicting instructional teacher leadership in a distributed leadership environment.

\section{Planning the two-phase study}

In the construction of the ITLRSBSC, instructional teacher leadership behaviors will be identified from themes extracted from research 
literature and professional educator groups. The populations of the sequential two phase study will be disjoint groups in geographically differing regions of the US. In phase one, a Q-set will systematically emerge from a) empirical literature b) conceptual models (see section 7.), and c) mixed method evaluation processes on interview and PIMRS data [12][13][14]. In phase two of the study, ITLRSBSC behaviorally anchored dimensions and subscales will be constructed utilizing the transferred Q-set within BARS methodology [5][14][15][16]. The researcher determined the necessity of a two population, twophase study due to a) the distinctions between shared leadership and distributed leadership and b) the differing implementations of formal school reform programs. The bidirectional multivariate relationship behavioral functions captured through the development of a Q-set have a transferring benefit to a BARS instrument development procedure [13][14]. Both populations will include principal leaders and teacher leaders practicing in complex organizational environments depicting these bidirectional relationship constructs. This investigation's effective use of Behaviorally Anchored Rating Scales (BARS) methodology necessitates the differing role group perceptions of both principle instructional leadership behavior (i.e. principal survey form of PIMRS) and teacher instructional leadership behavior (i.e. teacher survey form of PIMRS) [5]. The perceived augmentation of principle instructional leadership is theoretically superimposed on the design of the ITLRSBSC instrument [4][5][14][17]. Participants serving in phase one, practice in a setting where a formal distributed leadership initiative drives school reform, and the participants serving in phase two practice in a setting where formal distributed leadership initiatives are not identified. The inclusive populations, sequenced in the two phase instrumentation study, increase the likelihood of post development ITLRSBSC validation [13].

\subsection{Planning phase one methods: A transferrable Q-set from PIMRS and interview data}

The first population assists the researcher in the construction of a Q-set emerging from PIMRS crosssectional survey data and interview data. Retained from the PIMRS survey data and the interview data, school level aliases and educator aliases will assist the researcher in correlation analysis of principal and teacher instructional leadership perceptions. Correlation analysis and other systematic data handling outcomes (see section 7.3.), transfer to the study's phase two BARS methodology in the form of an initial Q-set and a convergent instructional leadership conceptual framework. Phase two development processes of the ITLRSBSC instrument, therefore, inherit incident behavioral practices sourcing from bidirectional multivariate relationships. The Q-set data also transfers data derived under a distributed leadership lens (see section 7.1.).

\subsection{Planning phase two methods: critical incident behavior refinement}

BARS

The second population assists the researcher in the further refinement of a conceptual model for ITLRSBSC emerging from BARS methodology (see section 8.) The Q-set transferred from phase one will be presented to 'Group 1' for BARS behavior to domain association of critical incident behaviors (see section 8.7.). The researcher presents each group with study model information used to facilitate reconsiderations of the Q-set transferred from phase one. The researcher observes the BARS phases for significant deviations from the models. Throughout the BARS processes, the researcher evaluates divergent construct data for contextualization overtones and justifies any data handling [12][17].

\subsection{Study phase and sub-phase architecture}

A representation of the investigations' two-phase design with sub-phases is outlined before presentation of each step.

Study phase one activity: Developing an emergent, transferrable Q-set and convergent instructional leadership conceptual model (see section 7.)[14].

1. Collect cross-sectional survey data, collect interview data, and synthesize leadership conceptual models data [4][5][13][17]

2. Analyze the data in a mixed method evaluation design consisting of data integration processes: data transformation, typology analysis, extreme case analysis, and data consolidation [12]

Study phase two activity: Further development of the transferred convergent model. Transformation of the transferred Q-set, utilizing BARS behavior to domain association of critical incident behaviors, to instrument constructs (see section 8.)[14][15].

1. BARS Phase 1: Q-Sort the Q-Set retaining operational definitions [15]

2. BARS Phase 2: critical incident behavior consensus; eliminate critical incident behavioral examples based on a criterion level [16] 
3. BARS Phase 3: critical incident behavior performance scale determination [16]

The sequential use of data collection instrumentation, mixed method evaluation processes, and BARS methodology, encapsulate distributed instructional leadership measurement items within the emergent ITLRSBSC instrument. Preliminary findings from study phase one development (e.g. detailed semi-structured interview questions) will be presented in this timely publication (see section 7.1.). At the time of this publication, phase one PIMRS data collection is commencing. Subsequent manuscripts will report on additional findings. Replication studies are encouraged in part, or in full, to expedite future ITLRSBSC instrument version modifications. All paralleling research activity will begin to fill the blank spots of how and why distributed leadership systems engage instructional teacher leadership functions toward school improvement.

\section{Study phase one design: Q- methodology}

A discussion on the validity of the ITLRSBSC phase one Q-set begins with the identification and synthesizing of multiple sources; collectively conceptualizing the behavioral activity to be measured. The Q-set is specifically targeted at capturing instructional teacher leadership behavior enhancing school capacity toward student learning. A convergent synthesis of three leadership conceptual models guides Q-set emergence, and through data integration processes, yields an initial ITLRSBSC instrument model (i.e. post phase one model) [12][14]. Three models used are:

- Organizational Capacity in Schools model [4];

- $\quad$ PIMRS instrument model [5]; and

- $\quad$ Leadership for Learning model [17].

This investigation specifically utilizes a model conceptualizing school organizational capacity depicting a distributed leadership environment in which teacher leadership components coexist with principal leadership components [4]. This is consistent with the study's overarching purpose of analyzing leadership behavior as a function of organizations' systems thinking [10]. Highly valid instruments for principal instructional leadership are the Principal Instructional Management Rating Scale (PIMRS) and Vanderbilt Assessment for Leadership in Education ${ }^{\mathrm{TM}}$ (VAL-ED) instruments. These instruments partially provide cross-check theme validity [2][5] of Q-set development using the constant comparative method during data collection. The PIMRS model assists in understanding instructional leadership constructs [5][13]. The Leadership for Learning model provides a cultural multivariate relationship lens of instructional leadership [17]. Noteworthy here is the participants utilized during Q-set and instrument development will be teacher and principal co-educators in differing cultural contexts (see sections 7.2. and 8.6.). Phase one participants will utilize the PIMRS instrument forms. Providing additional cross-check validity on Q-set itemization will be emerging themes from specific literature reviews and expert researcher source identification as detailed in the next section. The empirical research sources guide Q-set development and subsequently guide ITLRSBSC development.

\subsection{Interview question empirical grounding}

Interview questions are systematically designed to gather data pursuant of the research questions and problem statement. Interview questions emerged from convergent empirical literature and conceptual models. This section details the activity. Subsequent interview questions listed are associated to their model constructs as Q1 through Q8. The following instructional leadership relationships and constructs were adopted from the study's models:

1. 'Organizational Capacity in Schools' model (items are pairwise bidirectional)[4].

a. Leadership (Principal and Distributed) Q1, Q2, Q3, Q5, Q7, Q8

b. Professional community Q2, Q4, Q6

c. Program coherence Q3, Q4, Q5

d. Technical resources

e. Teachers' knowledge, skills, and dispositions Q1, Q6, Q7, Q8

2. 'Leadership for Learning' model (items are bidirectional with leadership)[17].

a. Vision and goals Q2, Q7

b. Academic structures and processes Q3, Q4, Q5

c. People capacity Q1, Q6, Q8

3. PIMRS model dimension sub-constructs [5]

a. Frames the School's Goals Q2, Q7

b. Communicates the School's Goals

c. Coordinates the Curriculum Q3, Q4

d. Supervises \& Evaluates Instruction Q5

e. Monitors Student Progress

f. Protects Instructional Time

g. Provides Incentives for Teachers

h. Provides Incentives for Learning Q1

i. Promotes Professional Development Q6, Q8

j. Maintains High Visibility

The numeric list provided prioritization on the rewording of source article critical incidence 
behavior in the form of interview questions [15][16]. This process was applied to teacher leadership behaviors emerging from empirical literature rigorously selected according to selection criteria (see section 11.1). In this way, qualitative data collected in phase one is subsequently captured in the resulting Q-set according to a synthetization of the study's conceptual models. Contact the authors for specific source articles used to extract data and formulate questions systematically correlated to aforementioned models. Teacher interview questions emerging from this systematic extraction method and rewording paradigm are presented.

1. When you perceived a need to take a leadership action based on trust, why did you perceive school conditions of openness, respect, and integrity; forbearing the leadership action?

2. When you perceived a collective leadership change agency, why did you perceive school conditions existed conducive to your participation as a change agent?

3. When you perceived a need for curricula change, why did you proceed with a commitment to content or documentation changes? Did school perception influence how you made changes?

4. When you support cross subject activities as a leader, instructionally or its coordination; how was it done and why did you perceive that this benefited school improvement?

5. When you perceived a need in any school function variability beyond normal activity, how did you meet the challenge and why was this modality chosen to address the need?

6. When you contribute to professional development, how was it actualized and why did you perceive school conditions accommodating this particular developmental contribution?

7. Considering your perception on contributing to distributed leadership, how do you choose the context in which to implement your 'vision' oriented leadership activity and why did you choose that activity?

8. How do you perceive school level communication in instructional reflection and why did you lead in the area of instructional reflection and growth?

Principal interview questions will be reworded as appropriate retaining the same correlations to the synthetization of the study's conceptual models. As conventional with semi-structured interviews, the researcher will elicit any clarification on how and why practices were chosen. Responses of instructional leadership critical incident behavior will be coded for Q-set inclusion. While the question set is not the exhaustive set used in gathering data during phase one of the study, these sample questions are provided for design illustration. The questions are subjected to a small-scale trial to assess delivery logistics and the quality of data received.

\subsection{Sample participants}

The population for this study's Q-set development will be teachers with three or more years of professional teaching experience in the United States. Professional teachers perform predominantly instruction services to primary, middle, and secondary levels of education.

A sample was found matching the study design and was accessible for both quantitative and qualitative data collection. In the State of Iowa, schools throughout the state participate in formal distributed leadership initiatives designed to drive school reform. Accepted schools and its educators participate in a statewide Teacher Leadership \& Compensation System (TLC). TLC participants engage the study through theoretical sampling to assist in Q-set development. Online documentation is extensive and facilitates the study's constant comparative methods and post data collection mixed method evaluation processes (see section 6.1.). Data sources are freely available through internet software learning management systems.

All PIMRS and interview participants are presented with a detailed explanation of the Qmethod process and subsequent mixed method evaluation processes. This will be done to decrease the potential for rater biases [16]. All participants will be informed with the purpose of the research activity. In compliance with informed consent standards, participants will receive the conventional information.

Decades of use of the PIMRS instrument suggests that detecting significance in leadership on learning predetermines the use of a large data set [13]. Although other samples may also provide the collection of sufficiently large data, it is found that Iowa's system of 76 TLC participating school districts have desirable representation properties. The districts span the state geographically and are inclusive of diverse communities.

Participant descriptive data is recorded using aliases for the purpose of finding correlation of distributed instructional leadership behaviors. Descriptive data on phase one participants, as well as phase two participants, will assist the researcher in correlating school level educator instructional leaders' perspectives. 


\subsection{Analysis Strategy and the emergence of a Q-set}

The instructional leadership perceptions are captured into quantitative and qualitative data by the PIMRS instrument and semi-structure interviews respectively. Study phase one data analysis will begin with a series of school level bivariate correlation calculations among sub-constructs of PIMRS quantitative data. A correlation process was chosen over other statistical methods due to the goal of creating Q-set items capturing school level constructs depicting bidirectional multivariate leadership relationship.

Independently, NVivo software will be utilized to detect emergent themes based on school level qualitative data. The researcher will make observations between the findings of both independent data type specific processes, incorporating other school level data sources appropriately through the process known as triangulation.

The goal of constructing a Q-set capturing teacher instructional leadership critical incident behavior data may necessitate the utilization of two mixed method data evaluation processes; data transformation and typology analysis.

Data transformation in both directions between data types, contribute to understanding distributed instructional leadership multivariate relationship behavior [12][13]. Data transformation increases the likelihood of finding significance in the correlation of principal and teacher instructional leadership critical incident behavior [12][16].

Typology analysis is utilized to categorize distributed instructional leadership behavior data in the form of a Q-set. The typology analytical strategy also illuminates applicability of the study's guiding frameworks and facilitates the emergence of the ITLRSBSC framework [12][14]. As designed, the perceived augmentation of principal instructional leadership is theoretically superimposed throughout the process of creating the Q-set [14]. The Q-set is transferred to phase two of the study.

\section{Study phase two design: Behaviorally Anchored Rating Scales (BARS)}

Behaviorally Anchored Rating Scales are common in quantifying educator behaviors for quality assessment. BARS instruments continue to have support in analysis of educator performance from early instructional leadership periods through current educator effectiveness rating systems [5][15][16]. BARS instruments must be developed under rigorous methodology for anchor dimensions to accurately quantify the behavior the instrument is intended to measure [16][18].

The development of the Instructional Teacher Leadership Rating Scale for Building School Capacity (ITLRSBSC) by this investigation follows the five step iterative process of BARS development [15].

- First, select a representative sample group of raters for generation of the ITLRSBSC [16].

- Second, the group determines the strongest supported dimensions retaining the operational definitions [16].

- Third, the group identifies behavior incidents (retaining instructional teacher leadership terminology) and general statements representing degrees of performance to the behavioral incidents [16] [18]. ITLRSBSC dimensions and subscales may not be finalized chronologically in the process [15].

- Fourth, a different representative sample group, representative of the same population as the first group, eliminates behavioral examples based on a criterion level of subscale behaviors to dimension assignment [15][18].

- Finally, another group, which could be the first group, is asked to describe satisfactory and unsatisfactory teacher behavior across the dimensions. In this final step, the group assigns point values compared by the researcher to a discrimination index for each behavior [15][18]. Behavior items above a criterion level will be retained for their mean point values and used in the format of the ITLRSBSC.

The following is a description on how this study will execute the five general steps on creation of the ITLRSBSC.

\subsection{Dimension construction and scale dimension construction sources}

The dimensions of an instrument designed to measure instructional teacher leadership will be NVivo theme derived from four sources:

1) Literature review articles on teacher leadership, instructional leadership, and school capacity building.

2) King \& Bouchard dimensions of school capacity model [4].

3) PIMRS instrument and Leadership for Learning model [5] [17].

4) Expert opinions of domains containing effective observable instructional leadership behaviors for school improvement [5]. 


\subsection{Dimension theme emergence}

Using the NVivo data analysis program, nodes will be determined from sources on instructional teacher leadership. The nodes will be coded under words and definitions according to rigorous criteria guiding construction design (pre-instrument). It is important to note that the school organizational capacity model depicting distributed leadership environments where instructional teacher leadership and principal instructional leadership behaviors coexist in proven empirical use prevents circular reasoning invalidity [14][19]. Post-instrument validity assessment is according to psychometric analysis and empirical literature evidence (research literature evaluation according to standards in systematic reviews of research). From the node and word pattern analysis, illustrations will be generated.

\subsection{Dimension subscale identification}

Theme emergence will suggest dimension subscales for instructional teacher leadership for building capacity in schools. It is important to note the literature review on teacher leadership, proven instruments on principal instructional leadership, a school capacity conceptual model for distributed leadership, and expert educator opinion on instructional leadership produce the subscales. The author will use these subscales to develop the constructs of instructional teacher leadership for building capacity in schools. A psychometric property analysis of the data derived from instrument implementation will support the researcher's instrument constructs.

\subsection{Teacher critical incident behaviors}

Theme emergence will also suggest instructional teacher behaviors (BARS critical incident actions) [5][16] for instructional teacher leadership in building school capacity. A research based construct (domains, subscales, and teacher behaviors) will have been partially developed. A detailed group of education professionals will participate in refining the constructs for instructional teacher leadership conducive to capacity building in schools.

\subsection{Scale development participants}

The population for this study scale development will be teachers with three or more years of professional teaching experience in the United States. Professional teachers perform predominantly instruction services to primary, middle, and secondary levels of education.

\subsection{Study phase two sample participants}

The Pennsylvania State System of Higher Education (PASSHE) consists of 14 member universities including East Stroudsburg University of Pennsylvania (ESU) and Indiana University of Pennsylvania (IUP). The ESU members of the partnership cohort program, ESU/IUP Administration and Leadership Studies, will be comprised of teachers and administrators from primary, middle, and secondary schools throughout PA and NJ. It is important to note here that the use of these "co-educator" participants is highly necessitated by instrument dimension construction validity (see section 6.). The following independent groups will be systematically selected and reduced randomly from eligible ESU cohorts three through seven. All groups will be presented with a detailed explanation of BARS and Q-method processes before participating in any of the designated tasks. This will be done to decrease the potential for rater biases [16]. The following expert groups will be designed as disjoint groups for the purpose of increasing construct validity of the finalized instrument.

BARS Group 1: ESU doctoral cohort subjects who maintain a teacher position $(n=12)$.

BARS Group 2: ESU doctoral cohort subjects who maintain an administrator position $(n=9)$.

BARS Group 3: ESU doctoral cohort program subjects who maintain an administrator or teaching position $(\mathrm{n}=18)$.

BARS Group 4: ESU/IUP doctoral cohort program subjects who maintain an administrator or teaching position $(n=30)$.

\subsection{ITLRSBSC item construction}

BARS Phase 1 - Initial behavior to domain association for instructional teacher leadership

BARS Group 1:

- Three groups will be formed of four participants $(n=12)$. Each group will be assigned the task of ranking (Q-sort) the piles of critical incident behaviors already divided into dimension groups (Q-set) from the dimension construction phase of the methodology. Dimension change requests are permissible by notation on Q-set items.

- The groups will be additionally charged with recommending changes in the behavior terminology.

- At the conclusion of the twelve participants' work, two volunteers from each group will convene with the author to integrate and edit the work of the initial groups [16]. 
- The resulting ranked behaviors will be presented to the group of twelve for approval.

- Each rater will be then be requested to provide three critical incident behaviors reflecting good, average, and poor behavior examples for each critical incident behavior.

BARS Group 2:

- Three groups will be formed of three participants $(n=9)$. The group will be assigned the task of reviewing the work of Group 1 supplementing and revising (as necessary) dimensions and behavior examples [16].

BARS Phase 2 - Behavior to domain list association for instructional teacher leadership

BARS Group 3:

- Three groups will be formed of six participants ( $\mathrm{n}=18$ ). Each individual of the group, independent of the Phase 1 groups, will be provided a list of dimensions and a single randomly ordered (Q-set) of critical incident behaviors associated with instructional teacher leadership (combined sets created from BARS Phase 1). Each behavior will be assigned to dimensions according to the raters.

- At the conclusion of behavior assignment to dimensions by the group, critical incident behaviors that were not assigned by a $60 \%$ consensus of the group to a single dimension were eliminated from further analysis. Behaviors not clearly reflective of leadership constructs would counter the objective of constructing a valid instrument.

BARS Phase 3 - Critical incident behavior assignment of values

- Three groups will be formed of ten participants $(n=30)$. The groups will be presented a list of domains and associated behaviors from phase 1 and phase 2, synthesized by the researcher. Each individual of the group will be then tasked with assigning values on a 7 point performance scale (very poor 1 through very good 7) those examples created in phase 1 and surviving the phase 2 census processes.

- Example items with a standard deviation greater than 1.5 will be eliminated from further analysis. The consensus process of phase 2 , and the behavioral item measure of central tendency criteria of phase 3 , provide for agreement of the assessed value and dimension association of any particular behavioral example [16].

The researcher rewords behavior examples of instructional teacher leadership from actual anchor behavior language to expected behavior language. The researcher maintains the operational terminology produced by the expert groups. An instrument user (rater) can compare behaviors easily when examples are reworded in expected behavior language [5].

\section{Pilot administration of ITLRSBSC Survey}

A small-scale trial of the ITLRSBSC self-report instrument will be conducted to assess delivery logistics and report on preliminary psychometrics. The BARS Group 4 subjects $(\mathrm{n}=30)$ will be randomly reduced from systematically selected members of the combined groups of experts participating in the construction of the instrument. Survey delivery will be via survey monkey. The researcher is aware of the bias tendency of utilizing the same group for pilot studies and instrument design, but the author feels that the delivery experience is essential. A second implementation of the survey instrument will be administrated on a more representative sample of the population consisting of teachers from the ESU College of Education

\section{Administration of ITLRSBSC Survey}

The subjects of a larger ITLRSBSC administration will be randomly reduced systematically invited participants from ESU College of Education graduate programs. Graduate programs will be selected to provide study participants representative of teachers with a variety of experiences. Participants will report institutional level (elementary, middle, secondary), years of total service, and years served in their current institution.

All participants will be informed with the purpose of the research activity as in the pilot group. In compliance with informed consent standards, participants will receive the conventional information.

\section{Measurement properties of the ITLRSBSC instrument}

Paralleling the development of the PIMRS instrument, the following criteria will be used to assess the teacher leadership self-report instrument:

- empirical grounding,

- content validity,

- reliability,

- $\quad$ validity, and

- construct validity using subscale intercorrelation and conceptual-empirical linkage [5]. 


\subsection{Constant comparative empirical grounding}

Empirical grounding of instructional teacher leadership constructs depends on the quality of literature reviews. As earlier mentioned, BARS instrument development also requires this rigor. As designed, the perceived augmentation of principle instructional leadership is theoretically superimposed on the design of the ITLRSBSC instrument. This was accomplished in part through the transferal of a Q-set from phase one of the study to phase two. The same rigor of quality literature selection and review, therefore needed to be applied to the Q-set development. The detailed account of interview question origination accounts for this level of Q-set development, and the detailed origination of the ITLRSBSC instrument model dimensions. A valid Q-set will translate into high validity scores through instrument psychometric processes. Criteria in a conceptual framework have been developed for standards in systematic reviews of research [6]. These criteria have been applied to principal instructional leadership reviews and were adapted to instructional teacher leadership reviews; predetermining Q-set construction. The conceptual model criteria are as follows:

1. guiding purpose,

2. conceptual framework guides,

3. search criteria and procedures,

4. explicitly communicated and defensible source identification,

5. procedures justification,

6. composition of group of studies, and

7. communication of findings, limitations, and implications of the study [20]

\subsection{Instrument validity}

Factor analytic methods used on the data collected by the instrument will reveal internal consistency across education institution levels (elementary, middle, and secondary). Conceptually, instructional teacher leadership has behaviors identifiable throughout education institutions K-12. After data collection, a one-way ANOVA will compare within-level variance to between-level variance. In all subscales, a one-way ANOVA should fail to reject the null hypothesis denoting there is no significant difference in the perception of instructional teacher leadership behaviors across institution levels.

\section{Assumptions, limitations, and delimitations}

A delimitation of this two-phase study is the use of samples that were constrained to geographical regions within the Commonwealth of Pennsylvania, New Jersey, and the State of Iowa. The participating teachers and administrators for phase one of the study were selected from participants in Iowa's statewide Teacher Leadership \& Compensation System. The participating teachers and administrators for phase two of the study were selected from students attending a university of the Pennsylvania State System of Higher Education (PASSHE). It will be assumed these teachers are a diverse enough sample of educators pursuant of the author's goal of developing a widely portable instrument.

This study employed theoretical sampling and a probability sample selection to investigate constructs of instructional teacher leadership. As with any contextual study, caution should be taken when initially applying findings to any school situated in a unique setting. Notwithstanding these delimitations, conclusions of this study will provide insights into how and why teacher leaders engage in their instructional leadership behaviors. Further investigations will be needed to verify findings discovered during the construction of the ITLRSBSC instrument. As is conventional with instrumentation, version modifications will be made as experience with the instrument accumulates.

\section{Conclusions}

This in-progress study develops a BARS instrument for measuring instructional teacher leadership conducive to building school capacity (ITLRSBSC). The development of the constructs is systematically designed from emergent themes based on research sources and input from professional educators. Included in the theme development are conceptual models for improved school capacity and highly valid principal instructional leadership instruments. A full internal validity and reliability analysis will follow instrument development (psychometric results). It is the author's hope the instrument brings to its users data supported by research with an aim at understanding instructional teacher leadership within schools seeking to build capacity toward improved outcome based learning. It is not intended that this instrument be used for teacher evaluation. Findings on instructional teacher leadership, encountered in the instrument construction and validation processes, will be reported to the research community. 


\section{References}

[1] Lear, J., Godin, S., Werner, S., \& Flamisch, M. (2015). Distributed Leadership: Behaviorally Anchored Development of the Instructional Teacher Leadership Rating Scale for Building School Capacity (ITLRSBSC). Proceedings of the Canada International Conference on Education: CICE-2015. Infonomics Society. Mississauga, ON, Canada. pp. 158-164.

[2] Porter, A. C., Murphy, J., Goldring, E., Elliott, S. N., Polikoff, M. S., \& May, H. (2008). Vanderbilt Assessment of Leadership in Education: Technical Manual, Version 1.0. New York: The Wallace Foundation. Retrieved from http://www.wallacefoundation.org/knowledgecenter/school-leadership/principalevaluation/documents/vanderbilt-assessment-ofleadership-in-education-technical-manual-1.pdf Date: May 29, 2015).

(Access

[3] Mulford, B. \& Silins, H. (2011). Revised models and conceptualization of successful school principalship for improved student outcomes. International Journal of Educational Management, 25(1), 61-82.

[4] King, M. B., \& Bouchard, K. (2011). The capacity to build organizational capacity in schools. Journal of Educational Administration, 49(6), 653-669.

[5] Hallinger, P. (1983). Assessing the instructional management behavior of principals. Unpublished doctoral dissertation, Stanford University, Stanford, CA. ERIC Document No. 8320806.

[6] Spillane, J. P., Halverson, R., \& Diamond, J. B. (2001). Investigating school leadership practice: A distributed perspective. Educational Researcher, 30(3), 23-28.

[7] Margolis, J. \& Huggins, K. (2012). Distributed but undefined: New teacher leader roles to change schools. Journal of School Leadership, 22(5), 953-981.

[8] Neumerski, C. M. (2012). Rethinking instructional leadership, a review: What do we know about principal, teacher, and coach instructional leadership, and where should we go from here? Educational Administration Quarterly, 49(2) 310-347.

[9] Lambert, L. (2002). A Framework for Shared Leadership. Educational Leadership, 59(8), 37-40.

[10] Senge, P., Kleiner, A., Roberts, C., Ross, R., Roth, G., Smith, B., \& Guman, E. C. (1999). The dance of change: The challenges to sustaining momentum in learning organizations. Performance Improvement, 38(5), 55-58.

[11] Angelle, P. S., \& DeHart, C. A. (2011). Teacher perceptions of teacher leadership: Examining differences by experience, degree, and position. NASSP Bulletin, 0192636511415397.
[12] Caracelli, V. J., \& Greene, J. C. (1993). Data analysis strategies for mixed-method evaluation designs. Educational Evaluation and Policy Analysis, 15(2), 195207.

[13] Hallinger, P. (2015). Using the PIMRS in Future Research on Leadership and Learning. Assessing Instructional Leadership with the Principal Instructional Management Rating Scale. Springer International Publishing. Switzerland. pp. 131-160.

[14] Ramlo, S. E., \& Newman, I. (2011). Q methodology and its position in the mixed methods continuum. Operant Subjectivity: The International Journal of Q Methodology, 34(3), 173-192.

[15] Beebe, R. J. (1980). Use of the Behaviorally Anchored Rating Scale in Evaluating Teacher Performance. ERIC, EBSCOhost (Access Date: July 6, 2014).

[16] Harari, O., \& Zedeck, S. (1973). Development of behaviorally anchored scales for the evaluation of faculty teaching. Journal of Applied Psychology, 58(2), 261.

[17] Philip Hallinger. (2011). Leadership for learning: lessons from 40 years of empirical research. Journal of Educational Administration, 49(2), 125-142.

[18] Bernardin, H. J., \& Smith, P. C. (1981). A clarification of some issues regarding the development and use of behaviorally anchored ratings scales (BARS). Journal of Applied Psychology, 66(4), 458.

[19] Gauch, Hugh G. (2003). Scientific Method in Practice. New York (NY): Cambridge University Press.

[20] Hallinger, P. (2013). A conceptual framework for systematic reviews of research in educational leadership and management. Journal of Educational Administration, 51(2), 2. 